\title{
Contribuições do design de serviço em transporte público
}

\section{Contributions to service design in public transportation}

MENDONÇA, Bárbara Rangel de Carvalho Braga de; Mestranda; UEMG - Universidade do Estado de Minas Gerais

barbarademendonca@gmail.com

ALMEIDA, Marcelina das Graças de; Dra; UEMG - Universidade do Estado de Minas Gerais

marcelina.almeida@uemg.br

\section{Resumo}

O artigo explora a suspeita da contribuição do design de serviços ao contexto de transporte coletivo de Belo Horizonte. Para tal identificação, interessa discutir teoricamente as múltiplas interfaces do transporte e o gerenciamento do serviço de transporte. E por isso, o recorte apresenta alguns limites teóricos no debate da mobilidade orientada ao espaço, seja em conflito com as Tecnologias de Informação e Comunicação (TIC) ou com o Sistema de Informação de Transporte (SIT). Ambos os componentes contribuem com a interação do usuário, mas um caracteriza-se na qualidade do lugar especializado e o outro com a qualidade do sistema de transporte. Conclui-se a necessidade de organizar um quadro teórico a partir desta identificação para amadurecer posteriores avaliações dos componentes espacializados. Entre as lógicas de planejamento e execução dos projetos de serviço de transporte intermodal, o design deve refletir sobre a lógica intangível que acessa a ótica dos usuários e dos servidores.

Palavras Chave: Design de Serviços; Tecnologia de Informação e Comunicação; Sistema de Informação de Transportes.

\begin{abstract}
The paper explores the suspicion of the service design contribution being applied in the contexto of public transport in Belo Horizonte. For this identification, it is important to theoretically discuss the multiple interfaces of transportation and transportation service management. Therefore, the paper presents some theoretical limits in the space-oriented mobility debate, whether in conflict with Information and Communication Technologies (ICT) or with the Transport Information System (TIS). Both components contribute to users interaction, but one is characterized in the quality of the specialized place and the other with the quality of public transport. We conclude the need to organize a theoretical framework from this identification to mature later evaluations of integration components. Among the logics of planning and execution of intermodal transport service projects, design should reflect on the intangibility of users and servers.
\end{abstract}

Keywords: Service Design; Information and Communication Technology; Transportation Information Systems. 


\section{Introdução}

A orientação projetual do design teve sua transição entre o tangível ao intangível, e passa a figurar o domínio da criação de ações eficientes de interação. O projeto de design não se restringe a hegemonias históricas, que propunham o formalismo e ocularcentrismo estético, e por isso pode sugerir a preeminência da experiência atrelada a fatores psicológicos. A disciplina, então, adquire novos fundamentos e interpreta a orientação de diretrizes para serviços a partir do estudo das performances sensoriais. Talvez por causa desta qualidade, Forty (2007) nos relembra que as narrativas de progresso sempre guiaram as justificativas de design. O contexto do progresso tecnológico acompanha tais impactos e ainda nos retoma os efeitos da inovação como importante via de capacitação de interações mais efetivas e agradáveis (THACKARA, 2005).

Com a expansão de mercados globalizados, ao invés de simplesmente reagir ao mercado, empresas com sistemas sócio-técnicos complexos podem estimular dinâmicas inter-relacionais a moldarem novos formatos essencialmente intangíveis. E esta é a espinha dorsal do design: propor práticas de projeto orientada ao usuário, adequando-se às novas dimensões refletidas em sua contemporaneidade (THACKARA, 2005). Sobre o conceito de interface, no entanto, Bonsiepe (2011) adequou uma nova leitura, motivando a ideia da desmaterialização da interface mas ainda mantém embutida a ideia de múltiplos contatos. Os projetos em serviço também podem se preocupar com a totalidade de suas interfaces interacionais ao vislumbrar-se pela demanda de ações de seus usuários, mas este não é o seu princípio. Como revoga Secomandi (et al., 2011), a interface incentiva a evidência das atividades periféricas, que podem ser considerados como acessórios tangíveis a serviços que deveriam se manter essencialmente intangíveis.

Contudo, a interface começou a ser compreendida como o domínio mediador do usuário e o objeto desde meados do século XX. Um renomado casal de designers, Bernice Ray Eames (19121988) e Charles Eames (1907-1988), aplicavam os princípios do design thinking para a resolução de problemas estratégicos institucionais na IBM, empresa multinacional de tecnologia, entre 1950 e1970 (IBM, 2018). E impulsionaram para um público variado uma perspectiva sobre a Era da Informação, com um sistema de produto-serviços que orientaram missões educativas. Posterior a tal reconhecimento terminológico, a profissão do designer, que estava atrelada apenas ao desenvolvimento de produtos, passa a figurar o domínio da criação de ações eficientes de interações materializadas por conceitos. A disciplina adquire novos fundamentos, evoluindo a pesquisa de serviço para a facilitação de mudanças organizacionais de grandes grupos de pessoas.

Um panorama geral dessa atividade pode ser acompanhada pelo relatório de impacto global elaborado por uma rede de especialistas no setor que organizam-se na Rede de Design de Serviço (Service Design Network). E conta com atualmente com mais de 30 mil participantes filiados contribuindo para a legitimação do impacto econômico gerado pela aplicação do design de serviços (MAGER, 2016). E talvez por isso o campo de inovação tenha amadurecido seus métodos de mensuração, e o design recebe reconhecimento global devido a sua forte contribuição para os arranjos organizacionais.

Das relações descritas por Moritz (2005) sobre a função do designer (the role of designer), produtos apresentam as características 'do que' é produzido e serviços apresentam características 'com o que' são performados em experiências complexas. Essencialmente ambas as funções podem partir do mesmo princípio epistemológico, sistematizando conceitos que no entanto propõe soluções distintas. Thackara (2005) e Moritz (2005) associam a atuação do design de 
serviços às atividades que dão forma às relações com os consumidores em termos de sua essência 'como' serviço e 'por sua' comunicação. E Krucken (2009) observa que dentre os papéis do designer, o profissional também pode ser tradutor de informações para otimizar as dinâmicas interrelacionais em esquemas visuais. Em razão disso, atuam com flexibilidade para adaptar o direcionamento do projeto, visto que as melhorias, inovações e comunicação da perspectiva da organização são inseridas para as quais as propostas estratégicas se direcionam (MORITZ, 2005).

A partir de uma abordagem colaborativa e multidisciplinar, o designer relaciona os campos de conhecimento de forma holística. E para a Rede de Design de Serviços (MAGER, 2016), a conscientização do setor público quanto a uma oportuna melhoria e inovação são aplicáveis às capacidades de design. Nesse sentido a compreensão das demandas individuais e coletivas ao atendimento do serviço não significa apenas o reconhecimento das manifestações urbanas, mas a avaliação dos serviços internos em termos de investimento econômico.

\subsection{Problematização}

Ao construir um quadro teórico em serviços, Sangiorgi (2009) sumariza três práticas de investigação que merecem destaque e aprofundamento de pesquisa. São elas: a interação, definido por o que é qualidade nos serviços de interação e como isso pode ser projetado e avaliado; a complexidade, definido por quais são as qualidades e dinâmicas do sistema e o que é escalado e suas intervenções em design de serviços; e finalmente a transformação, sendo como e quando o impacto das práticas de serviços em organizações e comunidade de usuários. Estas áreas emergentes pode ser associadas à temas interdisciplinares como subsídio à pesquisa das práticas relacionadas, como, por exemplo, a mensuração em inovação no setor público.

O serviço público pode ser caracterizado como qualquer atividade fornecida à população em geral pela administração direta ou indireta do Estado, e sendo vinculado às regras do Direito público, atua de acordo com a legislação (JUSBRASIL, 2018). No cruzamento de contribuições das áreas de planejamento e design de serviços para o viés de diretrizes políticas, interessa compreender quais os papéis e contribuições do designer e do design, para que assim sejam determinadas intervenções efetivas e rentáveis a serem discutidas. De modo objetivo, suspeita-se que o design de serviço tem potencial para contribuir com diretrizes municipais no setor público de transportes.

Os serviços em Mobilidade devem ser amparados por objetivos sinérgicos entre a estrutura interna onde ocorre a administração pública, buscando atender à demandas apresentadas pela população. $\mathrm{Na}$ natureza dos problemas do serviço público, predominam-se incertezas e imprevisibilidades: são complexos, transfronteiriços e insolúveis pelas ferramentas e abordagens tradicionais do governo (AGUNE, 2017). O grande desafio é manter um mercado de inovação contínua com uso de novos métodos, técnicas gerenciais e novas ferramentas (TIDD, 2015). A integração intersetorial é uma forma de resolução de problemas complexos que podem aproximar a mensuração da inovação orientada pelo design de serviços: um vínculo entre a participação cívica em um conjunto de soluções em comunicação e de gestão interna.

\section{Referencial Teórico}

A revisão consistiu em dois tipos de trabalho, com destaque a difusão da cultura da inovação para o setor público europeu e um breve recorte dos serviços de transporte coletivo de Belo Horizonte, com o objetivo de despertar a vocação de estudos em serviço público 
intercontinentais. A orientação metodológica da inovação no serviço público, mencionado antes, podem ser adequadas às capacidades estratégicas do design. O que Mager (2016) obteve destaque foi o desafio de criar um embasamento teórico e metodológico, aos processos organizacionais e de interações que são orientadas pelo usuário, de forma consistente.

No relatório Design for Growth and Prosperity (COMISSÃO EUROPEIA, 2012) são direcionadas algumas recomendações ao design europeu "Leadership board" e apresentam o design para o setor de serviços como uma das cinco recomendações estratégicas de capacidade do design, estimulando a atuação e a implementação movidas pelo comportamento dos usuários. Nele ainda compreende-se o design como ferramenta de competitividade, porém, integra seu papel em áreas de negócios estratégico e gestão do design à produção centrada no usuário. 0 relatório destaca Barcelona, Londres, Milão e Paris como países internacionalmente conhecidos por aplicar o design no desenvolvimento de serviços públicos. E discorda da provisão europeia quanto a sua padronização em relação ao provedor, e destaca cidadãos, empresas e servidores como usuários.

O aumento de atores envolvidos transfere os desafios para aplicação das medidas demandadas pela população. Uma das preocupações quanto às demandas públicas são frente a necessidade de fornecer uma maior personalização de serviços - sendo mais flexíveis, ágeis e, em alguns casos, co-produzidos. E por conta da capacidade distributiva da inovação em uma vasta disponibilidade de ferramental interativos e colaborativos, combinadas com o recurso da Internet entre outros equipamentos tecnológicos, é possível alcançar a participação dos usuários. O que significa que os consumidores não são mais reconhecidos de maneira passiva ao projeto.

Para uma agência de serviços públicos, Participle, é fundamental desenvolver capacidades e relacionamentos que tragam novas abordagens para o envelhecimento, o trabalho familiar, desemprego e doenças crônicas. Para um dos fundadores, Charles Leadbeater ${ }^{1}$, a discussão formaliza-se nos modelos de organizações, para discutir as oportunidades de desenvolvimento da inovação aberta. Ao refletir sobre o interesse de participação dos usuários, reforça o momento propício em receber usuários desde a etapa de ideação, para implementar inovações incrementais em associação com as instâncias municipais das relações humanas em cada localidade - tal abordagem exemplificada pela NESTA (2018), organização não governamental da União Europeia.

Quanto a relação da necessidade, reforça que para atender um comportamento novo, impulsionar um sistema operacional a fazer mais "do mesmo" limita o potencial em fornecer algo diferente. Mager (2016) e Sangiorgi (2011) concordam ao demarcar a ineficiência em atender a determinado aumento de produtividade, padronização ou controle, sem que haja uma mudança clara de seus recursos internos com vista às estratégias e políticas que promovam tais iniciativas. A oportunidade de promover melhorias se fortalece por um diagnóstico que priorize implementações em políticas de inovação.

O Design Council (SEE, 2013), buscando formas de sensibilizar o design nas políticas de inovação produziu o relatório Design for public good, com a iniciativa de integrar uma rede de 11 parceiros europeus no programa SEE (Sharing Experience Europe). Dentre os governos nacionais e regionais são apresentando outros exemplos como Nova Zelândia, Coreia do Sul, Austrália e Cingapura, quanto ao uso do design orientando a inovação para o crescimento e a

\footnotetext{
${ }^{1}$ Charles Leadbeater, designer colaborador da Think-Tank, Instituto de consultoria para diretrizes políticas, e um dos fundadores da Particle, junto à Hilary Cottam e Hugo Manassei. Acesso em: <http://www.participle.net/>.
} 
competitividade. É nesse sentido que demonstram o papel significativo do design na mudança de cultura organizacional do setor público em concretizar novas práticas. O relatório apresenta com clareza o impacto do Design Thinking em superar "falhas estruturais comuns na prestação de serviços e na formulação de políticas" (SEE, 2013:5).

Os impactos mapeados são normalmente relacionados a aplicação do design de serviços em entender quais equipes, departamentos e especialistas são relevantes para um problema e envolvê-los em colaboração em diferentes níveis de atividades. Nesse sentido, como uma ferramenta diagnóstica, o processo de inovação orientado pelo design (design-led innovation process) pode ser representado em diferentes graus de aplicação (Fig. 1). O primeiro abrange pequenos projetos, como aplicativos mediadores de um serviço que tornam a tecnologia útil à interações com as pessoas. O segunda refere-se a cooperação de todos os envolvidos como agentes, no sentido em que absorvem as técnicas de design e a operam diariamente, mesmo como não-projetistas, desenvolvendo novas capacidades. A terceira facilitação dos designers encontra-se à nível de diretrizes políticas, acompanhado desde sua formulação para engajar pessoas de fora do governo também (SEE, 2013).

Assim como apresentado pelo relatório do Design Council (SEE, 2013), a relevância do engajamento cívico é marcada pela qualidade e eficiência do serviço fornecido do início ao fim de sua entrega. Em uma análise mais atenta, CatDrew, projetista sênior de políticas públicas do Police Lab UK, distinguiu os impactos das elaborações 'feitas para o' ou 'em conjunto com' os cidadãos (MAGER, 2016). O papel transformativo do design está atrelado apenas a sua abordagem, com combinação de práticas que promovem desde soluções específicas à organizacionais, e provoca colaborativamente o estímulo ao uso de ferramentas e capacitações práticas de inovação orientada ao usuário. Sangiorgi (2011) vai mais adiante em defesa a forma com que o design muitas vezes é associado a um paradigma assistencialista, envolvendo mais que um modelo de entrega, para destacar a profunda importância do modelo de capacitação centrado no conceito de co-criação e cidadania ativa.

As estratégias de transformação de inserção do design ocorrem interno às organizações, para garantir uma cultura de design centrada no ser humano e melhorar as provisões do serviço entregue externamente, ou são também mudanças de fora para dentro, em conjunto com a comunidade e partes interessadas para propor novos modelos de serviços e imaginar novos sistemas. Ambas devem ser avaliadas quanto à mudanças e práticas úteis e combináveis para um impacto de relevância. E nesse sentido a importância de transferir conhecimento entre os projetos e pesquisas está em fornecer uma base mais sólida para a construção de tal atividade. Em uma distinção simples, pode-se dizer que o design feito para o usuário celebra a orientação do projeto de design por observação (SEE, 2013). Enquanto o co-design, feito em conjunto com o usuário, no sentido estreito do termo, refere-se ao processo de design aplicado a co-operação criativa da imersão de seus usuários (fig. 1), com diversos especialistas, clientes e usuários para contribuir com o encaminhamento compatível aos objetivos do projeto (STEEN, 2011).

Figura 1 - Modelo de mudança de abordagem no co-design 


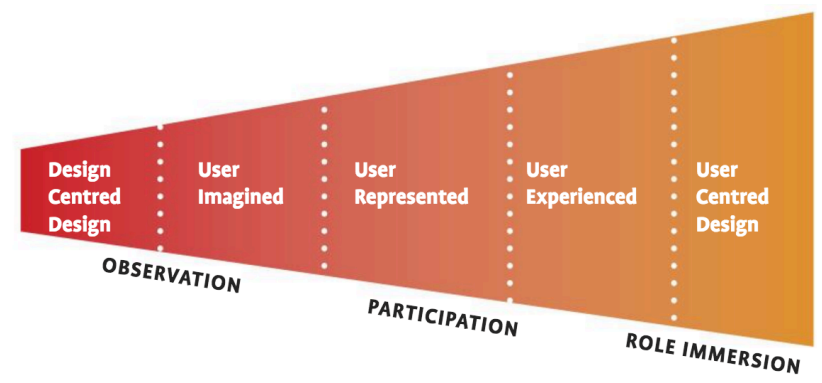

Fonte: retirado de Moritz (2005:35 apud Design Council, 2005-04-23

User Centred Design Conference, 2003-05-12, UIAH, Helsinki, Bill Gavers

O engajamento, não obstante, torna-se um impacto quantificável a partir de como os critérios são formulados e como os serviços funcionam no dia-a-dia (MAGER, 2016). Alguns profissionais e os seus clientes, bem como suas áreas de atuação, foram mapeados (fig. 2) e apresentaram sua participação em serviços do setor público como designers nas mais diversas áreas, com destaque aos serviços de Saúde, Educação, Comunicação, Juventude e Transporte (ESRC, 2012 apud MAGER, 2016).

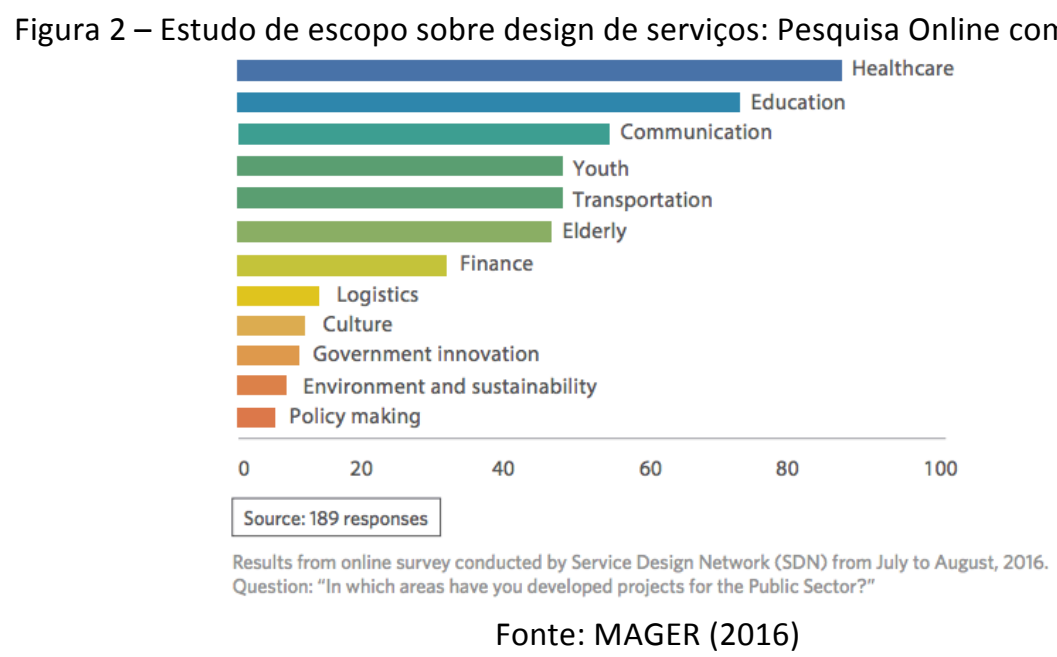

A esse respeito, o setor de serviços no Brasil é ilustrado pelo Instituto Brasileiro de Geografia e Estatística, onde "O principal destaque foi para os transportes, serviços auxiliares aos transportes e correio, que teve crescimento de 1,2\%, seguido pelos serviços profissionais, administrativos e complementares, que avançou 1,7\%" (IBGE, 2018). E destacando o próprio IBGE, apresentado pelo estudo de Szpiz (et al, 2015), a avaliação do uso do design em serviços só pode ser diagnosticada se promover serviços orientados para o gerenciamento das atividades promovidas pelos operadores de diferentes setores e demais atores que o utilizam.

\subsection{Benefícios do design de serviços}

No setor de design de serviços, houve um estímulo para a consolidação de um discurso tecnológico, entre gerenciamento de serviços e engenharia, onde o projeto da infraestrutura de serviços recebeu atenção primária como origem das discussões do design (SECOMANDI, 2013:35). Em busca do estabelecimento de uma iniciativa precisa de impacto, Moritz (2005) identifica os benefícios do design ao usuário e à organização mutuamente. Em teoria, a satisfação do cliente é formulada para ser útil, apta ao uso e desejável, enquanto a organização satisfaz-se pela efetividade e eficiência do aumento de sua produtividade (fig. 3). 
Figura 3 - Visão geral do modelo de aplicação do Design de serviço

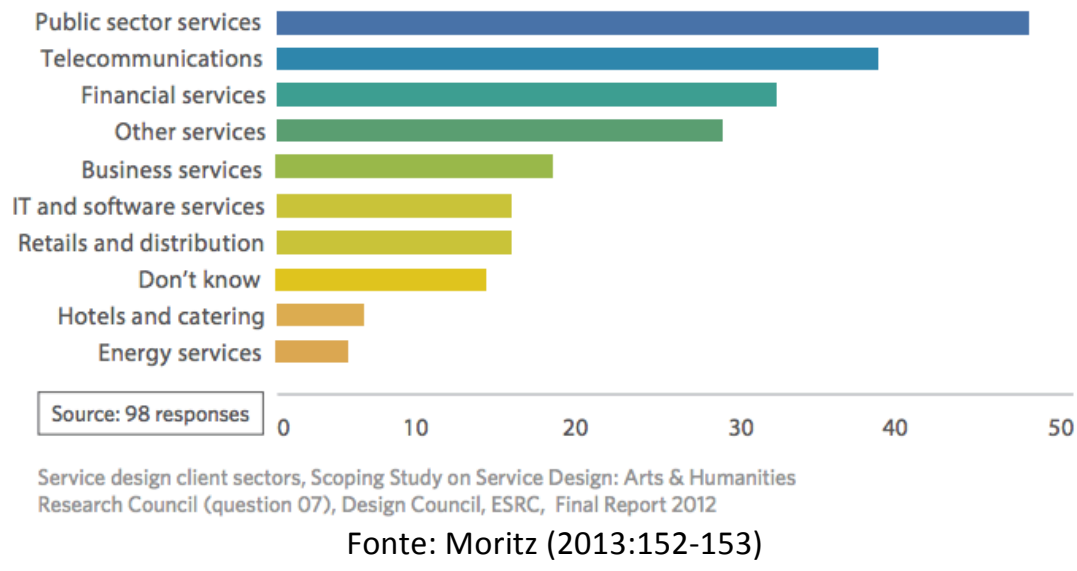

Moritz (2013) apresenta essa relação de satisfação a partir de dez indicadores de mudança: 1. Verdadeira compreensão das necessidades do mercado; 2. maior valor com os recursos disponíveis; 3. Mudança de cultura organizacional; 4. novas perspectivas sobre o desenvolvimento futuro; 5. maior eficácia; 6. melhor eficiência; 7. Aproximação entre organização e clientes; 8. experiências de serviço de maior qualidade como base de sucesso; 9. diferenciação contra a concorrência; 10. afinidade com a marca.

Para os pesquisadores Steen, Manschot e Koning (2011), além do próprio projeto em design de serviço, considera serem beneficiados os usuários e a organização servidora. Após um estudo de caso foram elencados benefícios identificados por: melhorias quanto a ideação do processo, definição do serviço e redução de falhas, bem como melhorias no gerenciamento do desenvolvimento. Destaca-se a probabilidade dos benefícios serem experienciados depois da entrega do mesmo, podendo ter alto grau de diferenciação da percepção do serviço e apropriação às reais necessidades dos clientes e usuários, gerando melhor experiência e maior satisfação. Mas são principalmente as medidas de longo prazo que aumentam a confiabilidade e contribuição educacional aos usuários. Como resultado, os benefícios identificados para a organização foram o melhoramento da criatividade, foco em clientes/usuários, avanços na relação entre prestadores do serviço e clientes, entre outros. Cabe expor que, as transformações disruptivas são geradas quando os atores sociais sentem a necessidade de participar do movimento, deixando de ter uma atitude passiva na recepção das mensagens, para uma atitude participativa (ERTHAL, 2015).

Sob a perspectiva de estabelecer os recursos sócio-técnicos no contexto das relações de troca do design, Secomandi e Snelders (2011) recorre às áreas de marketing, administração, engenharia e economia e atribuem como parâmetro a: co-produção de serviços, interface e infraestrutura e materialidade. Tais domínios são discerníveis por algumas nuances relativas a atribuição de papéis entre os atores sociais envolvidos à vista de Shostack ${ }^{2}$, Edvardsson e Olsson ${ }^{3}$, Ramaswamy ${ }^{4}$, Gallouj e Weinstein ${ }^{5}$, respectivamente. Segundo Secomandi e Snelders (2011), a

\footnotetext{
${ }^{2}$ Shostack, G. Lynn. 1987. "Service Positioning through Structural Change." Journal of Marketing 51 (1): 34-43.

${ }^{3}$ Edvardsson, Bo and Jan Olsson, Key Concepts for New Service Development, The Service Industries Journal 16:2 (April 1996): 140-64.

${ }^{4}$ Ramaswamy, Rohit. 1996. Design and Management of Service Processes: Keeping Customers for Life. Reading, MA: Addison-Wesley.

${ }^{5}$ Gallouj, Faïz, and Olivier Weinstein. 1997. "Innovation in Services.” Research Policy 26: 537-556.
} 
interface e a infra-estrutura são como uma contrapartida da prestação do serviço centrado no usuário a partir do próprio recurso sócio técnico de co-produção, e ambos podem ser considerados uma preocupação material pelo design de serviços, mas de naturezas distintas.

Condiz dizer que tais co-produções são formas de relacionamento ou interação, entendidas então, como atividades humanas a partir de trocas entre provedores e clientes, em diferentes graus de comunicação. A contribuição das pessoas como recursos humanos serão sempre abstratas e inerentes aos indivíduos, mas ao desenvolver relações de trocas por treinamentos adequados, direcionam um comportamento baseado na materialidade correspondente de suas interfaces. Em suma, Secomandi e Snelders (2011) revelam os relacionamentos como recursos tangíveis de infraestrutura realizados através da interface, quando mobilizados.

Esse entendimento sugere a Secomandi e Snelders (2011) que as dimensões sócio-culturais do serviço só podem ser experienciadas pelas pessoas em interação com interfaces materiais, incluindo as relações de serviço interpessoais. E assim não totaliza a natureza dos pontos de contato como sendo apenas interfaces tangíveis, mas reforça que a interface cliente-provedor traz novos serviços à existência. Cabe comentar a isenção de serem concentrados em processos, associados a bens ou ainda comparados à sua relação sócio-econômica da co-produção para justificar uma eventual tomada de decisão. São apresentadas, portanto, oportunidades ao design de produtos em adquirir novos fundamentos na pesquisa de serviços.

Por conseguinte, a infraestrutura pode influenciar a percepção dos clientes sobre os serviços pois assume os recursos de organização e controle relacionados à estrutura organizacional, sistemas administrativos e gerenciamento de marketing. E também por isso, o ambiente físico constitui um elemento importante dos pré-requisitos de serviço processados pelos clientes nas interfaces. Pela definição de Secomandi e Snelders (2011:14): “A interface de serviço materializa uma relação de troca entre provedores e clientes, e que o design da interface de serviço, talvez mais do que qualquer outra coisa, é o design do próprio serviço".

É necessário destacar as narrativas complementares aos critérios de deslocamento e informações ao pedestre. O artigo propôs organizar o contexto do design de serviços de transporte na sua interlocução com a tecnologia e participação de usuários no espaço urbano. $E$ considera os componentes concretos das Tecnologias de Informação e Comunicação (TIC) representativos ao conceito de sistemas de computação urbana como os próprios dispositivos integrados no espaço. Nesse sentido, ao compreendermos a infraestrutura dos serviços podemos inquirir os componentes concretos dos projetos de interface do serviço de transporte como os próprios meios de reconhecimento de interação do serviço completo.

\subsection{Domínio de informação do espaço urbano}

Interessa ao estudo em questão relacionar as qualidades dos ambientes urbanos com as aplicações físicas dos componentes digitais de TIC. Tal orientação considera o modelo de interação humano-computador para relacionar a interação dos recursos computacionais e sócio-técnicos integrados no espaço. O tema surte reflexões sobre o papel do designer como intérprete dos desejos e comportamentos dos usuários em espaços pensados para transformar a realidade social.

Como um cenário de atuação, a forma de ocupação e utilização do espaço são acolhidas pelos avanços tecnológicos em comunicação e transporte. Os novos simbolismos atribuídos a materialidade dos objetos, que buscam aperfeiçoar o monitoramento pela interdependência 
tecnológica, promovem distinções culturais hiper-locais nas relações espaciais e distinguem a satisfação de necessidades relativas às questões mentais do sujeito, não antes possíveis. A suspeita de que os componentes tecnológicos poderiam aproximar e prescindir do espaço, por sustentar sua dissolução na arquitetura, orientou o estudo pela compreensão da contribuição do espaço como respaldo sócio-técnico.

O domínio de informação, na verdade, é argumentado em estudos da lógica social do espaço como o abordado por Hilier e Hanson (1984). Os autores argumentam que a movimentação e fluxos de deslocamento são uma influência dos percursos por ele sugeridos, e por isso, a configuração espacial condiciona a acessibilidade e hierarquiza os conceitos de integração e segregação. Neste sentido, os autores desenvolvem uma pesquisa dos arranjos configurados sobre os territórios por um modelo de sintaxe espacial que privilegia a disposição física dos elementos construídos para o pensamento urbanístico.

Nas ciências sociais, Castells (1996), define o interesse pelos recursos da linguagem virtual que são processadas e gerenciadas por meios tecnológicos, não se restringindo a um estudo espacial particular. Talvez por não limitar o processo de produção social a uma única lógica, Castells (1996) considerou diversos fatores de influência à sociedade conectada, dissolvendo a relação do lugar em um espaço-fluxo (network societies). A intenção de examinar as características de desempenho da rede depende de dois atributos fundamentais: a conectividade, definida pela capacidade estrutural que torna possível a comunicação entre os atores da rede; e a coerência, entendido como o compartilhamento de interesses em comum entre os objetivos autônomos dos atores em rede.

A dificuldade de interpretação interdisciplinar conduz ao resgate de valores e convenções sociais pertencentes a um contexto tecnológico espacializado. Se do fenômeno social fosse possível particularizar experiências subjetivas utilizando apenas métricas intrínsecas às dinâmicas socio-técnicas, ainda assim, tal orientação é uma perspectiva relacionado ao ser no espaço. É nesse sentido que as linhas de estudo da computação calma direcionam a experiência social para a ação tecnológica como um fenômeno de linguagem do espaço, com a preocupação de tornar objetiva as diferentes realidades apresentadas no espaço incorporado.

Muitas vezes são conferidos ao uso de TIC uma oportunidade de melhoria, e até mesmo como convocatória à atuação da comunidade. As interfaces das redes de comunicação foram tão evoluídas a partir das TIC e são tão necessárias quanto as necessidades da sociedade, que dão forma a tais novas tecnologias globalmente, superando fronteiras à comunidade digital. Se a tecnologia possibilitou que a comunicação entre cidadãos ocorresse por ferramentas gratuitas, interfaces intuitivas e de fácil utilização, ela também é responsável pelo crescimento econômico que deu abertura para a criação deste mercado. No entanto as TIC são aceitas como um dispositivo de comunicação e não garantem a qualidade do serviço oferecido.

Um exemplo disso são as contribuições de informações geográficas voluntárias, por crowdsourcing e VGI (Volunteered Geographic Information), definidas por ferramentas participativas utilizadas pela população para contribuir com anotações geo-referenciadas espacialmente e disponibilizadas na Internet (MENDONÇA; SANTOS, 2016). Com o Sistema de Informação Geográfica (GIS) presente nos artefatos digitais as ferramentas também movimentam informações dos usuários e movimenta o interesse em articular novos setores em serviços de compartilhamento. No entanto, Attard, Haklay e Capinei (2016) organizam a tipologia de vários 
setores em serviços de informação e incluem o Transporte Público, a exemplo do Moovit e Traveline, como serviços de escala local com informações convencionais de domínio privado.

Antes de abordar a integração espacial, é preciso reconhecer a interpretação das teorias de planejamento de espaços urbanos e sua aproximação com os domínios de informação. Isso, pois, ao relacionarem as características empíricas de desenvolvimento científico, dão suporte ao enfoque do design, preocupado com a atividade humana assim como em diversos campos de conhecimento. Como comentado por Souza e Malard (2010) e Souza (2008), a relação do lugar espacializado é representado pela informação ao mesmo tempo que o fenômeno da informação pode dar suporte às atividades humanas.

Em contribuição aos desafios existentes para gerir os serviços em transporte, antes seria necessário confirmar se os espaços oferecem características fundamentais para organizar a complexidade da comunicação humana. Uma abordagem feita por Souza e Malard (2010:8) buscou convergir as teorias a respeito do lugar ao contribuir com a premissa de que "os elementos espaciais são eles mesmos a informação", por meio das quatro qualidades fundamentais dos lugares (fig.4): territorialidade, privacidade, identidade e ambiência (MALARD, 1992). Conforme a autora, esses elementos informam as características dos eventos promovidos no espaço.

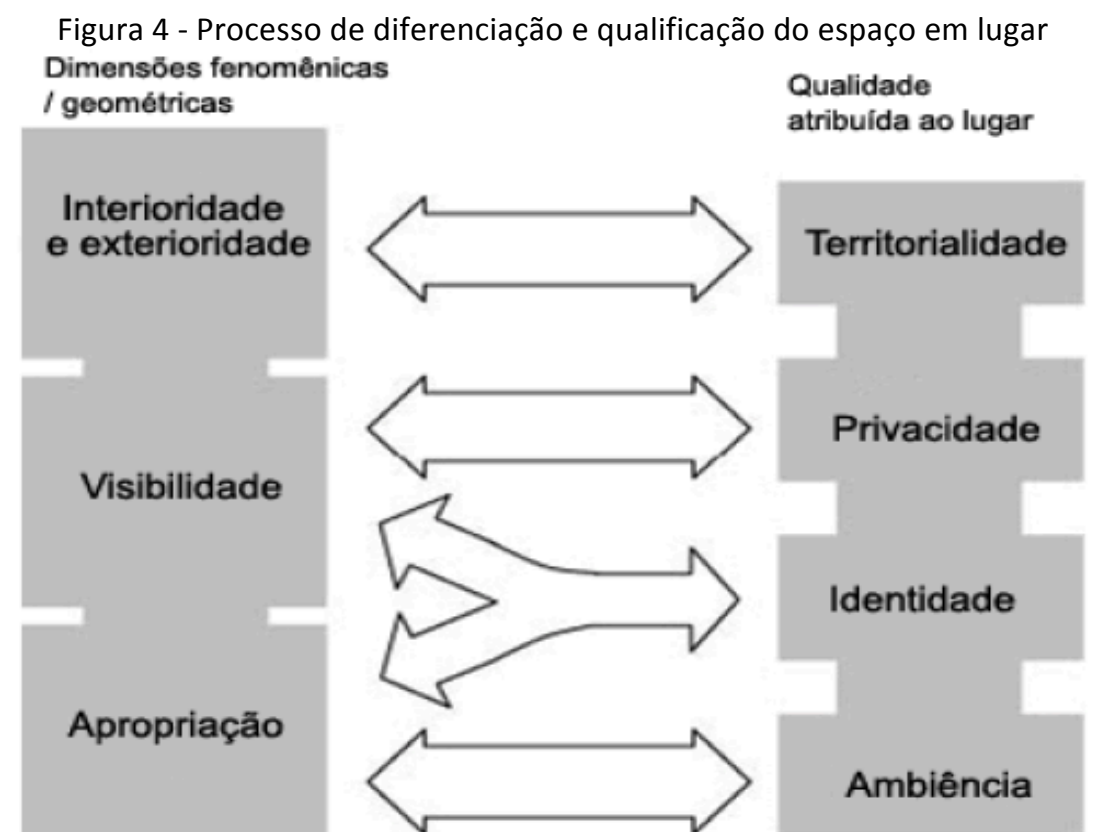

Fonte: Esquema adaptado pelos autores Souza e Malard (2010, apud MALARD, 1992)

Nesse sentido, as atividades humanas revelam sua integração ao mundo físico ao passo que os "elementos espaciais de um lugar recursivamente modificam e são modificados por seus habitantes" (SOUZA; MALARD, 2010:8). E tais atividades apropriadas no espaço são o resultado de eventos, ou seja, interações entre as pessoas e os espaços que são, por exemplo, ajustados pela interface do serviço que está sendo entregue ali. Ainda segundo Souza e Malard (2010:8), os eventos estão "em um contínuo processo de ajuste através do qual os distúrbios são minimizados".

Ademais, cabe compreender os elementos concretos apresentados nos serviços de transporte e no lugar-espacializado como eventos que participam do fenômeno da mobilidade. 
Estes são abordados aqui a partir dos acontecimentos de apropriação decorridos nas estações de ônibus. Cabe definir que a qualidade do serviço de transporte coletivo deve ser avaliado como um bem fundamental para qualquer cidadão, e a migração para demais meios individuais é comedida à manutenção dessa garantia. Os atributos e fatores usados para medir a qualidade no transporte coletivo são particularmente importantes para a gestão do transporte. E por relacionar o transporte pela oferta de um serviço quantitativo, se em relação "a capacidade de transporte, cobertura do serviço e frequência" (COUTO, 2011:45), e qualitativos, como disponibilidade, frequência, pontualidade, velocidade, conforto, facilidades ("decorrentes de serviços acessórios ou infraestrutura"), segurança e custo para o usuário (COUTO, 2011:45).

No entanto, a percepção individual e conjunta desses fatores pela população varia bastante em função da condição social e econômica, da faixa etária, sexo, etc. Por isso, Eloísa Antunes (2009), em sua dissertação, faz um estudo psicométrico para analisar a qualidade dos principais critérios de avaliação da qualidade do transporte coletivo (ANTUNES, 2009:31). Para os critérios estabelecidos por Ferraz e Torres $(2001$; 2004) foi proposto um parâmetro de avaliação, desenvolvendo a um padrão de qualidade para cidades brasileiras de médio porte, baseado em alguns atributos de opinião do maior número de usuários possíveis. Os indicadores de qualidade do transporte público são: acessibilidade; frequência de atendimento; tempo de viagem; lotação; confiabilidade; segurança; características dos veículos; características dos locais de paradas; sistema de informação; conectividade; comportamento dos operadores; e estado das vidas, para garantir a representação de condições reais do sistema incluindo a estrutura, operação e economia (FERRAZ; TORRES, 2001).

Os sistemas de apoio ao espaço são os sistema de comunicação e sinalização presentes nos pontos de parada, abrigos e estações, refletindo certa organização do serviço com indicação adequada dos quadros de horários e mapas de trajetos e suas regiões contextualizadas, com abrigos ou estações com distâncias curtas. A conectividade espacial refere aos deslocamentos entre bairros e dos traçados que possibilitam as transferências entre linhas no sistema troncoalimentadoras com tempo de espera adequado. Sob o que relaciona-se a direitura da rota, este é um ponto que Ferraz (1991) relaciona a percepção do usuário, caso seja com muitos desvios no meio do percurso, por exemplo.

Assim, o estudo analítico sobre o desempenho, satisfação e oferta de transporte público podem basicamente ser organizado a partir das impressões dos usuários a estes fatores durante o uso do serviço, e por sua natureza empírica são importantes dados que devem ser considerados por todo o processo de produção e entrega do serviço para o usuário, a partir de técnicas para mensurar sua aplicação e representar a recuperação de demanda.

\subsection{A integração municipal intermodal}

O comportamento dos fluxos urbanos sempre foi incentivado de acordo com os interesses econômicos da época, mais do que para promover facilidade de locomoção ao usuário de cada localidade (HERMONT, 2013). O espelhamento do projeto urbano responde os trajetos executados entre bairros ou municípios, com a formação de um sistema de redes composto pela rede viária, rede de transporte coletivo, rede de caminhada de pedestres, rede ciclo-viária, pontos de conexão entre os modos de transporte e o sistema de logística urbana. E a combinação de redes, e sua capacidade de relacionar um processo comum de entrega identifica o processo de integração física (MICHAEL FELDMAN, 2002, apud ROCHAT, 2005). 
No setor de transporte são impactados o ambiente de gestão da mobilidade e logística urbana, principalmente por possibilitarem o desenvolvimento de um banco de dados que identifica o fluxo dos meios de transporte em integração, por exemplo. Abordar a mobilidade a partir da gestão da qualidade pode auxiliar a compreensão de questões de risco econômico. São coletados dados para o estudo do espaço urbano visando propostas econômicas, em vista a questões de ocupação do solo das áreas onde se instalam as estações de transporte público, áreas de transição para a acessibilidade.

Antes das ferramentas de operação, em termos da infraestrutura do serviço, Liliane Hermont (2013) relacionou o posicionamento defensivo da oferta de transporte público a ampliação da sua frota de atendimento para atrair o público com preferência pelo transporte individual motorizado. "O que seria desejável é que os sistemas de transporte público pudessem organizar-se e integrar-se de modo a tornarem-se mais eficientes no meio urbano" (HERMONT, 2013:8). Nesse sentido, o interesse do setor de serviço em comunicação não envolve questionamentos quanto ao gerenciamento de dados mas, principalmente, sua representação para os interesses públicos.

\subsection{A gestão da qualidade no transporte em Belo Horizonte}

A regulamentação do transporte público é fundamental para a organização de políticas de mobilidade, que são os principais instrumentos diagnóstico em questão da qualidade de transporte público. Dentre as inúmeras formas de gestão e execução do município, direta ou indireta, o serviço não acontece isoladamente para planejadores especialistas, cada vez mais afetados por externalidades (ANTP, 2007). A Política Nacional de Mobilidade Urbana, pela Lei no 10.134 e Artigo 24 da Lei Federal da Mobilidade Urbana (Lei n 12.587/2012), promove o planejamento, execução e avaliação da mobilidade e regulamenta os serviços de transporte público coletivo urbano (NTU, 2012). E no acompanhamento de legislações para a organização da malha viária foi estabelecido um Plano de Mobilidade Urbana de Belo Horizonte, o Plan-mob.

No caso de Belo Horizonte, a operação e gestão da mobilidade urbana foi acelerada com os avanços dos Sistemas Inteligentes de Transporte ou Intelligent Transportation System (ITS), que faz parte de um incentivo ao adensamento misto, no conceito de desenvolvimento Orientado pelo Transporte (Transit Oriented Development - TOD). O ITS funciona a nível técnico, como instrumento de integração da infraestrutura do serviço público, e foi 'popularizado' a partir da "introdução de sistema de bilhetagem eletrônica nos transportes públicos urbanos e pela adoção do sistemas de monitoramento de frotas de transporte de carga" (ANETU, 2013:8). Em um cenário de ubiquidade da informação, é mais uma ferramenta de Planejamento de uso e ocupação do solo e Políticas de transporte, o setor se beneficia com o desenvolvimento de Sistemas de Trânsito Rápido BRT (Bus Rapid Transit).

O sistema BRT MOVE, em Belo Horizonte, incorpora o sistema metropolitano e o metrô. Os ITS e sua aplicação para BRT combina a tecnologia em busca de algum tipo de padronização para possibilitar a sincronização dos dados durante o trânsito no Centro de Controle e Operação. O BRT formaliza-se a partir de métricas e ações integradas que, dentro do contexto urbano, "aprimoram o atendimento de desejos de viagem dos passageiros por um conjunto de condições estruturais" (ITDP, 2015:10). A comunicação dos operadores e as empresas por aparelhos instalados nos ônibus, permite sua análise dinâmica ou estática, ser processada e armazenada na empresa operadora "a jornada de trabalho dos operadores, abertura e fechamento de viagens, atualização 
dos arquivos de recarga e atualização da matriz de integração temporal" (ANETU, 2013:11).

O mesmo recurso de dados é codificado para disponibilizar as informações aos usuários nas estações de ônibus fornecendo com destaque a melhoria das condições de transporte dos usuários (ANETU, 2013). E é nesse sentido que se propõe estudar o funcionamento a nível técnico dos instrumentos de integração da interface. Os painéis eletrônicos implantados nas estações disponibilizam informações do serviço com painéis independentes daqueles destinados para propaganda, de modo a manter a sustentabilidade financeira do sistema (ITDP, 2016). Todas as capacidades dos componentes listados são importantes para classificar o seu relacionamento ao lugar.

Dos serviços de oferta ao transporte coletivo, o sistema de informação ao usuário (SIU) é organizado pelo Sistema de Apoio à Operação (SAO) (PBH, 2013). O SIU se responsabiliza pela adequação das atividades de hierarquização da informação e experiência digital, vinculadas ao usuário por: dispositivos embarcados de informação - como painéis de mensagens variáveis, alto falantes e displays digitais; dispositivos de informação no terreno, pelos próprios painéis de mensagem variável e câmeras digitais de CFTV; e mídias complementares, a exemplo das centrais de telefonia, rádio, TV digital, e via mapas interativos por telefones celulares e dispositivos móveis, a exemplo do aplicativo do próprio sistema SIT Bus e SIU Mobile, para aparelhos móveis (PBH, 2013). Quando operados todos os quesitos estruturais significa ter executado os serviços relacionados ao SAO, que permite de forma sistemática organizar a prestação de serviços de oferta de transporte coletivo, com o Centro de Controle de operações de trânsito; sistemas de localização automática de veículo ( $\mathrm{AVL}$ ) e sistema de vigilância embarcado nas plataformas ou pontos de ônibus (PBH, 2013).

\subsubsection{Atores}

Em termos de usuários e atores sociais envolvidos no sistema, a ANETU (2013) são identificados nove principais atores do ITS-BRT, sendo pessoa física ou jurídica ou conjuntos de interação ao longo do processo de operação. São eles: a. Agente de comercialização e controle de acesso; b. condutor de transporte (TP); c. controlador operacional (de TP); d. gestor (de TP); e. operador (de TP); f. passageiro; g. provedor de serviço intermodal; h. viajante; i. usuário. 0 conceito de usuário é o conjunto de toda a sociedade que utiliza direta ou indiretamente sistema de transporte público. As manifestações sociais determinarão os papéis em que os usuários se apresentam ora como pedestre, viajante, passageiro, ou ainda como motorista de transporte individual e "qualquer outro que se beneficie dos serviços oferecidos" (ANETU, 2013:45).

\subsubsection{Funcionalidades ITS}

Pela complexidade de tantos usuários, a relevância de utilização do ITS está na qualidade do serviço, e por isso, o caráter estrutural do sistema de mobilidade está no: ordenamento, pontualidade, segurança, controle e informação ao cliente. Dentre suas funcionalidades se aplicam sete grupos: Planejamento, Programação e Gestão, Prevenção e Segurança, Infraestrutura, Marketing e "Imagem BRT", Coordenação Multi-modos, Tarifação Eletrônica e Informações aos Usuários dos Serviços BRT (Externos) (ANETU, 2013). Tais funcionalidades são consideradas como TIC e passam a ser atribuídas para gerenciar o fluxo de tráfego em prol do transporte público, em aplicação conjunta às políticas de tarifação ou restrições de acesso viário à zonas sensíveis. Tais estratégias à medida que articulam-se com trocas de informações tornam-se serviços "inteligentes" em transporte público e tráfego, pois apresenta aumento da eficiência em 
serviços de demanda e prevenção de acidentes (ANETU, 2013:50).

Dentre as funcionalidades apresentadas e a respeito de seus pontos de contato diretos ou indiretos, o papel com os usuários são cruzados assim como um provedor de serviço intermodal, por exemplo, quando transpõe o papel de condutores para viajantes (ANETU, 2013:45). Os principais tipos de utilização de ITS são apresentados como sub-sistemas visto suas tecnologias de apoio, tais quais: Sistema avançado de informação ao viajante (ATIS), Sistema Avançado de Controle de Tráfego (ATMS), Sistema Avançado de Controle Veicular (AVCS), Operação de Veículos

Comerciais (CVO), Sistemas de Controle de Serviços de Emergência (EM), Pagamento Eletrônico de Pedágios (ETC), Sistema Avançado de Transporte Público (APTS) (PBH, 2013). Destaca-se dos ITS, no subsistema APTS, como Infraestrutura aos serviços auxiliares e interfaces então representadas nas estações, buscando integrar o sistema de informação ao usuário (SIU) e Marketing e "Imagem BRT", responsável pela adequação das atividades de hierarquização da informação e experiência digital. O SIU está integrado ao SAO, mencionado acima, e permite que tais funcionalidades descritas sejam recebidas e prestadas informações ao usuário sobre os serviços a partir: de dispositivos embarcados de informação, como painéis de mensagens variáveis, alto falantes e displays digitais; dispositivos de informação no terreno, pelos próprios painéis de mensagem variável e câmeras digitais de CFTV; e mídias complementares, a exemplo das centrais de telefonia, radio e TV digital, e conexão à internet via mapas interativos por telefones celulares e dispositivos móveis, a exemplo do aplicativo do próprio sistema SIT Bus e SIU Mobile, para aparelhos móveis (PBH, 2013).

Nesse sentido, é importante endereçar que nos dois modelos de abrigos urbanos apresentados pela BHTrans no vetor Municipal, apresentam-se adaptações ubíqua a que se referem, na integração com as linhas alimentadoras, os componentes analógicos e digitais como: Câmera de segurança (A); Painel de horários (informação de chegada) (B); Exploração de publicidade (C); Iluminação - interna de LED (D); Mapas e rotas (E); Wi-Fi (em teste) (F). Contrastando-o com os dispositivos embarcados de informação encontrados no recorte teórico exposto anteriormente integrados aos abrigos ubíquos do MOVE. Para ilustrar os artefatos e serviços atrelados as estações de ônibus BRT em Belo Horizonte:
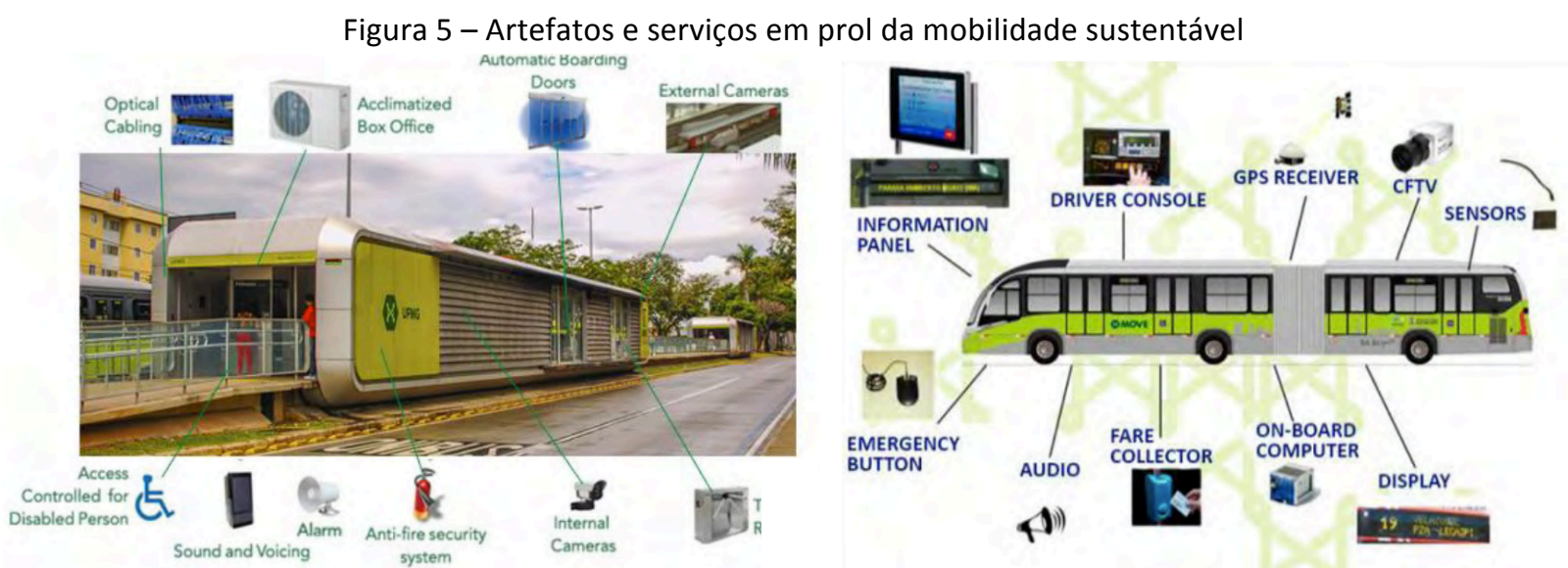

Fonte: PBH (2016)

Sob essa ótica, mesmo que todos esses componentes de TIC articulem-se entre diferentes modos de transportes, produzem desafios distintos de integração quanto a minimização de 
conflitos espaciais ao usuário. O conceito de como as práticas urbanas estão sendo atualizadas no imaginário tecnológico dos usuários depende do quanto os equipamentos são percebidos e relacionados. Quanto a operacionalização dos serviços demonstrados, profissionais orientados pelas teorias e práticas interdependentes, em termos de fluxo de trabalho, desempenham papéis específicos de diversos domínios semânticos. E nesse viés, muitos destes recursos técnicos são oriundos do setor de comunicação, ciência da computação, administração, entre outros, antes de serem incorporados em prol da mobilidade urbana. Os objetivos estratégicos do Plano e Programa de Mobilidade urbana sustentável (PBH, 2015) devem ser traduzidos e interpretados pela informação e comunicação integrada nos serviços de transporte intermodais.

\section{Considerações dos componentes informacionais do espaço}

Ao passo que as pessoas associam a configuração tecnológica à um modelo mental de espacialização, este representa um estado de intenção que passa a identificar tal mediação. Ou seja, os componentes eletrônicos interagem como pista contextual no âmbito de realização de alguma ação e, assim, aumenta o engajamento do usuário com o contexto espacial, por representar tarefas específicas à ele (MCCULLOUGH, 2006). E é nesse sentido que a teoria espacial incorpora componentes digitais para compreender a contribuição desses serviços midiáticos para o serviço de mobilidade.

Para McCullough (2006), as camadas de informação das experiências urbanas foram intensificadas e flexibilizadas, assumindo o gerenciamento das atividades sociais. E por meio dos fluxos de informações, organizações e práticas, e também pelas configurações físicas e intencionais, que os ambientes são inferidos como informação. Em outras palavras, cada vez mais a interpretação de fatores contextuais de cada local depende da capacidade configuracional do espaço em oferecer pistas conhecidas e consistentes por meio de suas camadas de abstração semânticas (MCCULLOUGH, 2006).

Ademais à identificação dos componentes informacionais de representação do lugar descritos acima, os fatores de qualidade espacial podem se referir a benefícios intangíveis quanto ao conforto percebido dos usuários. E são complementares aos efeitos da ambiência, das quais a qualidade relaciona à "todos os eventos que tornam o lugar aprazível, tangendo dimensões subjetivas através dos quais os indivíduos experimentam o lugar" (SOUZA; MALARD; 2010:11). Nesse aspecto, recomenda-se serem analisados questões sobre o conforto ergonômico, estudos de taxonomia e a própria compreensão psicológica, para uma aproximação de resultados qualitativos.

E a partir das qualidades atribuídas ao lugar, descritas por Malard (1992), é sugerido o reconhecimento dos elementos de territorialidade, privacidade, identidade e ambiência, para a realização deste estudo. Com o interesse de desenvolver um quadro teórico, a partir do método de avaliação pós-ocupação, e orientar uma posterior avaliação dos aspectos do ambiente de integração física sob a ótica do usuário e dos servidores. O simples reconhecimento das instruções disponibilizadas em dispositivos móveis, através do uso do aplicativo SIU-Mobile, no direcionamento espacial interno às estações, pode ser um indicador de conflito dos sistemas informacionais disponíveis na relação empírica de territorialidade, mas não totaliza a pesquisa.

Assim como na proposta apresentada por Souza (2006), onde o autor destaca um relatório 
de percepção do espaço ao constatar tais fenômenos espaciais em conflito com as atividades humanas, será adaptado um método de identificação de conflitos como via de identificação de defeitos na estação. Assim, a apropriação do espaço da estação Vilarinho será descrita pelos elementos de informação que atuam em conflito com o uso promovido pelos usuários. 0 interesse, com isso, é sugerir uma avaliação da apropriação espacial dos componentes eletrônicos, sejam eles softwares e hardwares, responsáveis pelo serviço informacional para os usuários da estação Vilarinho. Entende-se que este projeto pode auxiliar a destacar elementos do espaço que funcionam mal e, por isso, podem estar interferindo na adoção ou contribuição do uso das TI pelos usuários, evidenciando a necessidade de remodelação das apropriações espaciais das TI disponíveis na estação.

É necessário destacar tais metodologias tradicionais e complementares aos critérios de deslocamento de integração e informações espaciais para que estes sejam cruzados com os dados geo-referenciados para o estudo de mobilidade. E ao organizar a interlocução teórica da sintaxe espacial com a tecnologia, pensar a participação dos usuários para identificar oportunidades para o design de serviços. E por isso, a representação dos componentes de TIC ao conceito de sistemas de computação urbana é uma contribuição aos próprios dispositivos de TI integrados no espaço, mas principalmente uma forma de medir a percepção da população sobre ele. Nesse sentido, ao compreendermos a dimensão da infraestrutura dos serviços de transporte podemos inquirir os componentes de interface implementada como os próprios meios de reconhecimento espacial de interação do serviço.

\section{Conclusões}

Para permitir a interpretação sistêmica dos fatores então abordados por Souza e Malard (2010) são supostas, da literatura em design de serviços, ainda tímida à complexidade que envolve o serviço de transporte, algumas contribuições para a visualização da interferência do espaço ao modelo mental de serviços. Tendo em vista as contrapartidas estabelecidas pelos conceitos de design de serviços, as considerações que se fazem aqui relevantes ao tratamento dos domínios sócio-técnicos são relacionadas à infraestrutura espacial e a interface tecnológica dos serviços públicos de transporte. Foram correlacionados os estudos apresentados para serem traduzidos visualmente em futuras pesquisas que possam orientar uma comparação da avaliação técnica dos aspectos do ambiente de integração do sistema de transporte intermodal à ótica dos usuários e dos servidores.

As preocupações do design quanto ao projeto das interfaces são explícitas nas teorias de cada disciplina de projeto que o designer se debruça. O design de interação e de informação vão propor objetos de estudo que o design de serviço pode também "absorver", pois exploram as dinâmicas da relação humano-computador - mas serão, essencialmente, acessórios das ações estratégicas tangíveis. A partir da sustentação de propostas e iniciativas integradoras aos setores de serviço de transporte, o processo de design deve ser implementado a partir de um diagnóstico eficaz que envolva todos os seus usuários. Assim, as soluções para as fases de concepção à implementação dos projetos passam a garantir um impacto na entrega completa do serviço. Isso permite a co-criação, co-design e ao co-desenvolvimento serem integrados como uma oportuna interferência na entrega de demandas da população.

De modo objetivo, supõe-se que o espaço apropriado por componentes informacionais 
podem contribuir para a adoção ou rejeição de diferentes níveis de ferramentas de gestão, representada pelos canais de comunicação presente nos dispositivos móveis. Apesar destes canais ilustrarem dados geo-referenciados fornecidos pelo serviço de transporte, não contribuem como pista contextual da infraestrutura do serviço percebido pelo usuário. Sendo necessário confirmar, pelo estudo de verificação empírica, se a apropriação espacial destes elementos pode ser responsável por outras medições na orientação das TI que representem as interferências e adaptações espaciais necessárias à melhoria da percepção transversal do sistema de transporte coletivo. Propõe-se a análise das qualidades fundamentais destes espaços para orientar novas modalidades para componentes de $\mathrm{TI}$, como se comportam com os fenômenos espaciais e como podem ser avaliados para aumentar suas interações com o sistema. E assim, discutir iniciativas ubíquas de reprodução do espaço que traduzam um maior acesso aos demais meios de participação pelos usuários.

Nesse sentido, o contexto urbano de mobilidade levanta questionamentos sobre a identificação dos fatores que vão orientar o desenvolvimento econômico sugerindo a avaliação dos aspectos da interface. Este artigo levanta algumas questões aproveitando-se da Revisão do Plano de mobilidade de Belo Horizonte2020, visto que o estímulo ao uso do transporte público pode ao mesmo tempo gerar um tipo de visibilidade e acesso que aumente a percepção do sistema de transporte coletivo. Assim sendo, direcionou especial interesse em evidenciar os domínios da interface em transportes que devem ser estimuladas como uma base sólida para a construção da atividade do design de serviços, onde destacam-se a arquitetura e ambientação, sinalização e pontos de venda informatizados ou com operadores.

$\mathrm{O}$ ato de promover o desenvolvimento colaborativo de ideias locais deve ser acompanhado de iniciativas em inovação social. Sob essa ótica é sugestiva a aplicação do design de serviços na capacitação de recursos humanos com a iniciativa de preparar os servidores a exercer adequadamente suas funções utilizando-se da abordagem do design para a resolução dos problemas que podem ser tratados.

\section{Referências}

AGUNE, Roberto Meizi. Dá pra fazer - Gestão do conhecimento e inovação em governo. Seminário: Projetos Inovadores na Gestão Pública - 21 de Março de 2017. Disponível em: $<$ https://vanzolini.org.br/noticia/seminario-projetos-inovadores-na-gestao-publica-assista-aovivo/>. Acessado em: 14/06/2018.

ANETU, Associação Nacional das Empresas de Transporte Urbano. Sistemas Inteligentes de Transporte - ITS. Brasília: $2013 . \quad 53 p . \quad$ Disponível em: <http://www.ntu.org.br/novo/upload/Publicacao/Pub635889696401808391.pdf> Acessado em: 25/03/2018.

ANTUNES, Eloísa Maieski. Avaliação do transporte público por ônibus sob o ponto de vista do usuário em cidades médias paranaenses. Dissertação (Mestrado em Engenharia Urbana) Universidade Estadual de Maringá, Programa de Pós-Graduação em Engenharia Urbana, 2009. Disponível em: <http://www.peu.uem.br/Dissertao_Eloisa.pdf>. Acessado em: 20/03/2018.

ATTARD, Maria; HAKLAY, Muki; CAPINERI, Cristina. The Potential of Volunteered Geographic Information (VGI) in Future Transport Systems. Urban Planning, Vol. 1, Issue 4. Lisboa, 2016. 
Disponível:<https://www.um.edu.mt/_data/assets/pdf_file/0005/295430/VGlinfuturetransport. pdf>. Acessado em: 20/03/2018.

BONSIEPE, Gui. Design, Cultura e Sociedade. São Paulo, Edgard Blucher: 2011.

CELASCHI, F. Il design della forma merce: valori, bisogni e merceologia contemporanea. Milano: II Sole 24, Milano, 2000.

COMISSÃO EUROPEIA, European Design Innovation Initiative. Design for Growth and Prosperity. Report and Recommendations of the European Design Leadership Board. Published by DG Enterprise and Industry of the European Commission. Helsinkin, Finlandia, 2012. Disponível em: $<$ http://europeandesigninnovation.eu/wpcontent/uploads/2012/09/Design_for_Growth_and_Prosperity_.pdf>. Acessado em: 06/03/2018.

COUTO, Daniel Marx. Regulação e controle operacional no transporte coletivo urbano [Manuscrito] : estudo de caso no município de Belo Horizonte. Universidade Federal de Minas Gerais - Escola de Engenharia. Belo Horizonte, 2011. Disponível em: < https://www.ufmg.br/pos/geotrans/images/stories/diss007.pdf>. Acessado em: 05/03/2018.

ERTHAL, Ana. Sociedades em Rede, mídias digitais e novas configurações de diálogos. Curso de Formação de Gestores Públicos e Agentes Culturais. Edição 2015 - Rio de Janeiro, RJ. Disponível em: <http://www.cultura.rj.gov.br/curso-gestoresagentes/textos/redesmidiasdig.pdf $>$.Acessado em: 26/11/2016.

FERRAZ, A. C. P. Sobre a eficiência e a eficácia do transporte público nas cidades médias. Tese (Livre docência) - Escola de Engenharia de São Carlos, São Carlos, 1990.

FERRAZ, A. C. P.; TORRES, I. G. E. Transporte Público Urbano. São Paulo: RiMa, 2001. Disponível: <http://www.peu.uem.br/Dissertao_Eloisa.pdf> Acessado em: 10/08/2017.

FORTY, Adrian. Objetos de desejo - design e sociedade desde 1750. Tradução: Pedro Maia Soares, São Paulo: Cosac Naify, 2007.

HERMONT, Liliana Delgado. Oferta e demanda de transportes integrados [monografia]: um estudo de caso em Belo Horizonte. Dissertação (mestrado) - Universidade Federal de Minas Gerais, Escola de Engenharia. 2013. Disponível em: <https://www.ufmg.br/pos/geotrans/images/stories/diss034.pdf> Acessado em: 25/12/2017.

IBM. Good design is good business. Dispoível em: <http://www03.ibm.com/ibm/history/ibm100/us/en/icons/gooddesign/>. Acessado em: 02/04/2018.

IBGE, Instituto Brasileiro de Geografia e Estatística. Relatório no Setor de Serviços, 2018. Disponível em: <https://g1.globo.com/economia/noticia/setor-de-servicos-avanca-1-em-abrilaponta-ibge.ghtml>. Acessado em: 11/06/2018.

ITDP, Instituto de Políticas de Transporte e Desenvolvimento. Relatório de Recomendações do sistema MOVE segundo o padrão de qualidade BRT. Vetor MOVE Antônio Carlos. Belo Horizonte, MG: 2015. Disponível em: < http://itdpbrasil.org.br/relatorio-move/>. Acessado em: 16/03/2018.

JUSTBRASIL, Blog de Justiça Brasileira. Serviços públicos. 2018. Disponível em:<https://douglascr.jusbrasil.com.br/artigos/136827785/servicos-publicos>. Acessado em: 05/04/2018.

KRUCKEN, Lia. Design e território: valorização de identidades e produtos locais. São Paulo: Studio 
Nobel, 2009.

MAGER, Brigit. Service Design Impact Report - Public Sector. Service Design Network. 2016. Disponível em: <https://www.service-design network.org/uploads/sdn-impact-report_publicsector.pdf>. Acessado em: 06/03/2018.

MALARD, M. L. (1992). Brazilian Low Cost Housing: Interactions and Conflicts between Residents and Dwellings. Architectural Studies. Sheffield, University of Sheffield. PhD: 239.

MENDONÇA, Bárbara Rangel de Carvalho Braga de Mendonça; SANTOS, Dimitri. Metadesign e Sustentabilidade em Redes: Complexidade e construção de sentido. Cadernos de design/ Centro de Artes - UFPEL. RS: Pelotas, 2016.

MORITZ, Stefan. Service Design: practical access to an Evolving Field. Londres, 2005. Disponivel em: <https://issuu.com/st_moritz/docs/pa2servicedesign/4>. Acessado em: 06/03/2018.

NESTA, Fundação de Inovação. Página institucional. Organização-não-governamental. Londres: 2018. Disponível: <http://www.nesta.org.uk/areas_of_work/public_services_lab/>. Acessado em: 06/03/2018.

NTU, Associação Nacional das Empresas de Transportes Urbanos. BRT Brasil: a evolução das cidades. In: Belo Horizonte, Cidades e sistemas BRT Brasil. Disponível em: $<$ http://www.brtbrasil.org.br/index.php/brt-brasil/cidades-com-sistema-brt/belohorizonte\#.WaMq-ZOGMp8>. Acesso em: 02/12/2016.

PBH, PREFEITURA DE BELO HORIZONTE. Ações em prol da Mobilidade Sustentável. Apresentação do Plano Diretor de Mobilidade Urbana de Belo Horizonte - PlanMob-BH. Seminário Internacional Mobilidade Urbana e Meio Ambiente. WRI Brasil Cidades Sustentáveis. Março, 2016. Disponível <http://www.bhtrans.pbh.gov.br/portal/pls/portal/!PORTAL.wwpob_page.show?_docname=1041 0267.PDF>. Acessado em: 20/10/2017.

PBH, PREFEITURA DE BELO HORIZONTE. SITBUS, Sistema inteligente de transporte do município de Belo Horizonte. Especificação Funcional - Anexo VIII. Gestão de Transporte de ônibus. Belo Horizonte, 2013. $67 p$.

Disponível em: <http://www.bhtrans.pbh.gov.br/portal/page/portal/portalpublicodl/Temas/Onibus/gestaotransporte-onibus-2013/080320_SITBus_Anexo_VIII.pdf>. Acessado em: 10/08/2017.

PBH, PREFEITURA DE BELO HORIZONTE (b). Relatório final Plan-mob BH: Plano de mobilidade urbana de Belo Horizonte. Desenvolvido entre 2007 e 2010. 2010. Disponível em: <http://www.bhtrans.pbh.gov.br/portal/pls/portal/!PORTAL.wwpob_page.show?_docname=9604 263.PDF>. Acessado em: 20/10/2017.

ROCHAT, P.O. Transporte Intermodal Fomenta o Comércio Internacional e o Desenvolvimento Sustentável. 2005. Disponível em: http://usinfo.state.gov./journals/ites/1000ijep/ijep1012.htm. Acessado em: 10/08/2017.

SANGIORGI, Daniela. Transformative Services and Transformation Design. International Journal of Design, 5(2), 29-40. ImaginationLancaster, Lancaster University, Lancaster, UK. 2011. Disponível em: <http://ijdesign.org/index.php/IJDesign/article/view/940/344>. Acessado em: 10/03/2018

SANGIORGI, Daniela. Building up a framework for service design research. Imagination Lancaster, 
Scotland, 2009.

SECOMANDI, Fernando; Snelders, Dirk. The Object of Service Design. Design Issues: Volume 27, Number 3, Summer 2011. Massachussets Institute of Technology, 2011. Disponível em: <https://www.mitpressjournals.org/doi/pdf/10.1162/DESI_a_00088>. Acessado em: 25/02/2018.

SEE, Sharing Experience Europe. Design for Public Good. Design Council, Danish Design Centre, Design Wales \& Aalto University. Finlandia, 2013 Disponível em <https://www.designcouncil.org.uk/resources/report/design-public-good>. Acessado em: 05/02/2018.

SOUZA, R. C. (2008). A place-theoretical Framework for the development of IT in urban spaces. Architecture. Sheffield, The University of Sheffield. Ph.D.: 315.

SOUZA, Renato César F de; MALARD, ML. Uma Teoria Para a Aplicação da Tecnologia da Informação nos Espaços Urbanos. Revista da Universidade de Sao Paulo - Gestão \& Tecnologia de Projetos, v. 5 (Ed.1), pág. 1-23. Sao Paulo, 2010. Disponível em: <https://www.revistas.usp.br/gestaodeprojetos/article/view/50971>. Acessado em: 01/04/2018.

STEEN, Marc; Manschot, Menno; Koning, Nicole De. Benefits of Co-design in Service Design Projects. International Journal of Design. Vol. 5(2) August 2011. Disponível em: <http://www.ijdesign.org/index.php/IJDesign/article/view/890/346> Acessado em: 27/02/2018.

SZPIZ, Helga; MONAT, André Soares; PATROCÍNIO, Gabriel. Design de serviços no setor público: o design no Instituto Brasileiro de Geografia e Estatística (IBGE). Strategic Design Research Journal, volume 8, number 2. Rio de janeiro: 2015. Disponível em: < https://www.researchgate.net/publication/299574874_Design_de_servicos_no_setor_publico_o_ design_no_Instituto_Brasileiro_de_Geografia_e_Estatistica_IBGE>. Acessado em: 31/03/2018.

THACKARA, John. In the bubble: designing in a complex world. MIT Pres: 2005.

TIDD, Joe; BESSANT, Joe. Gestão da inovação [recurso eletrônico]. Tradução: Félix Nonnenmacher. 5 ed. Porto Alegre: Bookman, 2015. 